\title{
Crystal Structure of a Phycourobilin-Containing Phycoerythrin at $1.90-\AA$ Resolution $^{1}$
}

\author{
Stephan Ritter,*,2 Roger G. Hiller,† Pamela M. Wrench,† Wolfram Welte, $\ddagger$ and Kay Diederichs $\neq, 3$ \\ *Institut für Biophysik und Strahlenbiologie, Universität Freiburg, Albertstrasse23, D-79104 Freiburg, Germany; †School of Biol ogical \\ Sciences, Macquarie University, Sydney, New South Wales 2109, Australia; and \#F akultät für Biologie, Universität Konstanz (M656), \\ D-78457 Konstanz, Germany
}

Received December 22, 1998, and in revised form February 16, 1999

The structure of R-phycoerythrin (R-PE) from the red alga Griffithsia monilis was solved at $1.90-\AA$ resolution by molecular replacement, using the atomic coordinates of cyanobacterial phycocyanin from Fremyel la diplosi phon as a model. The crystallographic $\mathbf{R}$ factor for the final model is $17.5 \%\left(\mathbf{R}_{\text {free }}\right.$ $22.7 \%$ ) for reflections in the range $100-1.90 \AA$. The model consists of an $(\alpha \beta)_{2}$ dimer with an internal noncrystallographic dyad and a fragment of the $\gamma$-polypeptide. The $\alpha$-polypeptide (164 amino acid residues) has two covalently bound phycoerythrobilins at positions $\alpha 82$ and $\alpha 139$. The $\beta$-polypeptide (177 residues) has two phycoerythrobilins bound to residues $\beta 82$ and $\beta 158$ and one phycourobilin covalently attached to rings $A$ and $D$ at residues $\beta 50$ and $\beta 61$, respectively. The electron density of the $\gamma$-polypeptide is mostly averaged out by threefold crystallographic symmetry, but a dipeptide (Gly-Tyr) and one single Tyr could be modeled. These two tyrosine residues of the $\gamma$-polypeptide are in close proximity to the phycoerythrobilins at position $\beta 82$ of two symmetry-related $\beta$-polypeptides and are related by the same noncrystallographic dyad as the $(\alpha \beta)_{2}$ dimer. Possible energy transfer pathways are discussed briefly. 1999 Academic Press

Key Words: light-harvesting complexes; red algae; phycobiliproteins; protein structure; molecular replacement.

\footnotetext{
${ }^{1}$ This work was supported by the Deutsche F orschungsgemeinschaft/SF B 60 and by Macquarie University.

2 Present address: Medizinische Universitätsklinik Abt. Sportmedizin, Hugstetterstrasse 55, D-79106 F reiburg, Germany.

3 To whom correspondence should be addressed. Fax: ++49 7531 883183. E-mail: kay.diederichs@uni-konstanz.de.

${ }^{4}$ Abbreviations used: R-PE, R-phycoerythrin; B-PE, B-phycoerythrin; C-PC, C-phycocyanin; APC, allophycocyanin; PC, phycocyanin; PE, phycoerythrin; PCB, phycocyanobilin; PXB, phycobiliviolin; PEB, phycoerythrobilin; PUB, phycourobilin; rms, root-mean-square; NCS, noncrystallographic symmetry.
}

\section{INTRODUCTION}

The process of photosynthesis converts light energy to chemical energy. For the absorption of light, cyanobacteria and red al gae use water-soluble lightharvesting complexes, called phycobilisomes, which are attached to the stromal side of the thylakoid membrane. They have a molecular mass of approximately 7-15 × 106 $\mathrm{Da}$ and transfer the absorbed energy with an efficiency of over 95\% (Gantt and Lipschultz, 1973; Sauer, 1975; Glazer, 1989) to the photosynthetic reaction center.

Phycobilisomes are made up of two structural subunits: a core complex, located close to the reaction center, and rod-like segments that are attached to this core. Both subunits contain different phycobiliproteins in the form of stacked single discs. The various phycobiliproteins differ predominantly in the number and nature of the pigments they carry and therefore in their absorption spectra. Their arrangement is such that those absorbing in the blue/green region of the spectrum are located at the end of the rods, while those absorbing in the red region are located in the core complex.

The core complex consists predominantly of allophycocyanin (APC), ${ }^{4}$ with an absorption maximum $\lambda_{\max }$ at approximately $650 \mathrm{~nm}$, while the major constituents of the rods are phycocyanin (PC), with $\lambda_{\max }$ at $615-620 \mathrm{~nm}$, and phycoerythrin (PE), with $\lambda_{\max }$ at $495-565 \mathrm{~nm}$ (MacColl and Guard-F riar, 1987).

The polypeptidecomposition of cyanobacterial and algal phycobiliproteins is very similar. Two polypeptides of about $15(\alpha)$ and $17 \mathrm{kDa}(\beta)$ form an $(\alpha \beta)$ heterodimer, which is the basic structural unit in most phycobiliproteins. Each polypeptide of the basic $(\alpha \beta)$ heterodimer includes eight $\alpha$-helices $(X, Y, A$, $B, E, F, G$, and $H$ ). Their nomenclature points to the structural similarity of helices $\mathrm{A}$ to $\mathrm{H}$ to the globin fold (Schirmer et al., 1985). The positions of these helices are so conserved within the three-dimen- 


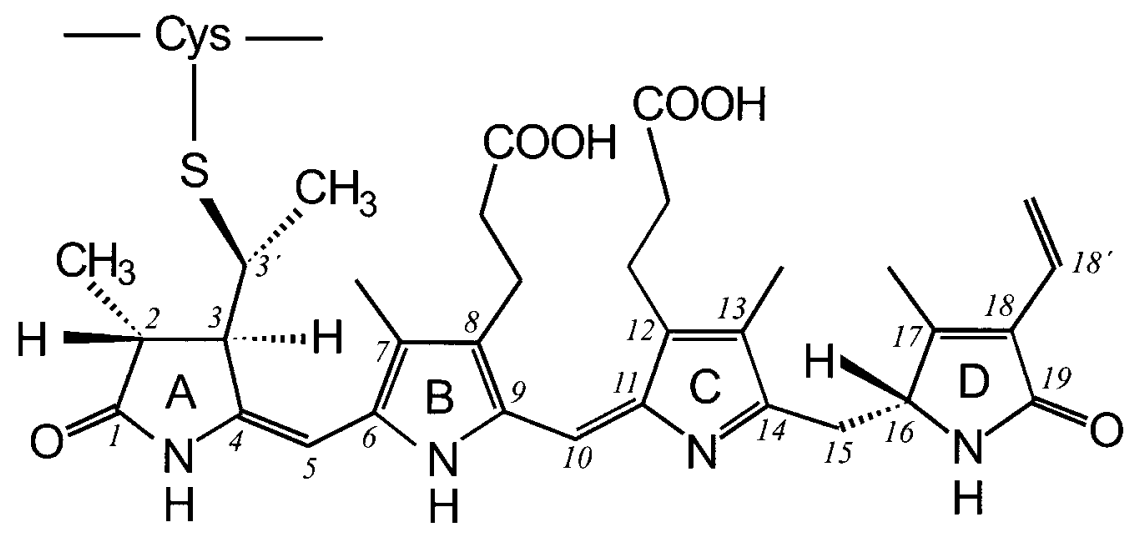

PEB (Phycoerythrobilin)

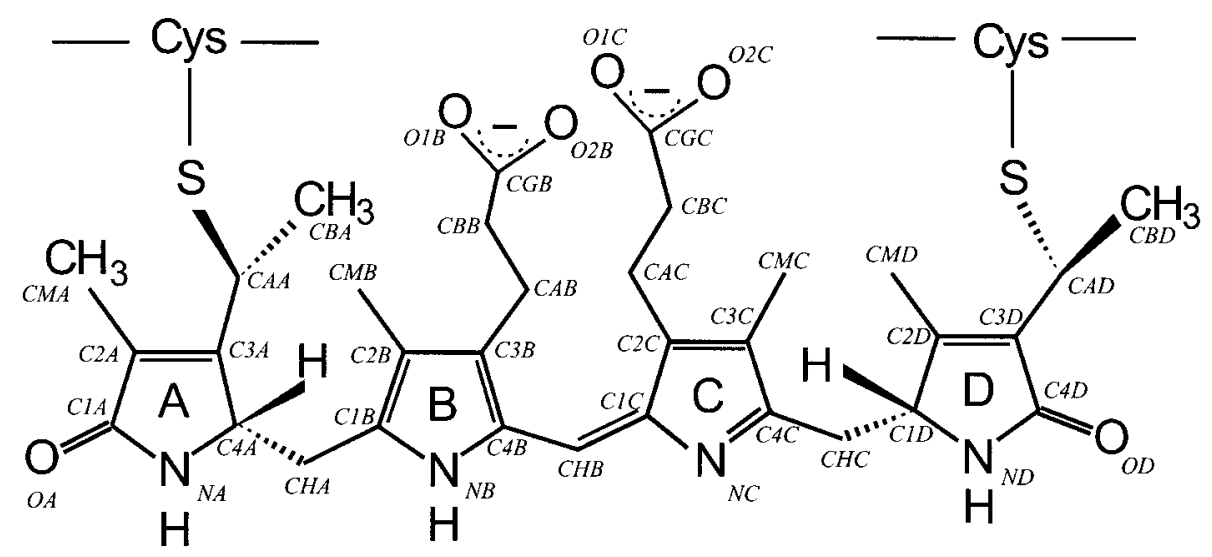

PUB (Phycourobilin, doubly linked)

FIG. 1. Chemical structure of the bilin chromophores (top) PEB and (bottom) doubly linked PUB. The nomenclature of the atoms is indicated.

sional structures that most of the more recent phycobiliprotein structure determinations could be done using the method of molecular replacement. The $(\alpha \beta)$ heterodimer is arranged around a crystallographic threefold axis to form an $(\alpha \beta)_{3}$ trimer. With few exceptions (Schirmer et al., 1985, 1987) this trimer is then related by a twofol d noncrystallographic symmetry (NCS) to form the $(\alpha \beta)_{6}$ hexamer. In addition, a third polypeptide of varying molecular mass is present and functions as a so-called linker protein (for reviews see Glazer, 1985, 1989; Huber, 1989; Grossman et al., 1993). In the case of R-phycoerythrin (R-PE) and B-phycoerythrin (B-PE), this linker protein ( $\gamma$-polypeptide) is pigmented, has a molecular mass of about $30 \mathrm{kDa}$, and is tightly bound to the $\alpha$ and $\beta$-polypeptides. This yields a stoichiometry of $(\alpha \beta)_{6} \gamma$ and a molecular mass of about $240 \mathrm{kDa}$ for both phycobiliproteins.

In R-PE and B-PE all pigments are open-chain tetrapyrrole chromophores (bilins), which are covalently bound to cysteines (Glazer et al., 1976). There are, however, differences in pigmentation. B-PE carries five phycoerythrobilins (PEBs) per $(\alpha \beta)$, while in R-PE two phycoerythrobilins (see Fig. 1, top) are attached to the $\alpha$-polypeptide, and two phycoerythrobilins and one doubly linked phycourobilin (PUB, see Fig. 1, bottom) are bound to the $\beta$-polypeptide. The pigment composition of the $\gamma$-polypeptide varies. For B-PE four bilins (two PEBs and two PUBs) are described (Glazer, 1985; Ficner et al., 1992) while for R-PE the amount of pigments varies from four to five bilins (PEB and PUB), depending on the organism. 
Up to three different $\gamma$-polypeptides are observed for R-PE of some species (Apt et al., 1993; Stadnichuk et al., 1993).

In the past few years the structures of various phycobiliproteins could be solved, showing the conformation of the bound chromophores within the protein (for review see Betz, 1997). The conformation of phycocyanobilin (PCB) was determined by Schirmer et al. (1985, 1986, 1987), Duerring et al. (1991), and Brejc et al. (1995). The conformation of phycobiliviolin (PXB), phycoerythrobilin, and phycourobilin was determined by Duerring et al. (1990); Ficner et al. (1992), Ficner and Huber (1993); and Chang et al. (1996); respectively.

In this paper we report the solution of the structure by molecular replacement and refinement of R-PE from the red alga Griffithsia monilis at $1.90-\AA$ resolution. The model consists of an $\alpha$-polypeptide carrying two PEBs at positions $\alpha 82$ and $\alpha 139$ and of a $\beta$-polypeptide carrying two PEBs at positions $\beta 82$ and $\beta 158$ and one PUB doubly-linked to residues $\beta 50$ and $\beta 61$. The two polypeptides $\alpha$ and $\beta$ are arranged around a NCS dyad to form an $(\alpha \beta)_{2}$ dimer as an asymmetric unit. In the following, residues on the NCS-related $\alpha$-polypeptides of the asymmetric unit are designated $A$ and $K$, respectively. Similarly, residues on the $\beta$-polypeptide are named $B$ and $L$, respectively.

Although the structure of R-PE from G. monilis is expected to be closely related to the structure of B-PE from Porphyridium sordidum and that of R-PE from Polysiphonia urceol ata, it is of interest because it was refined to high resolution using the native sequence of G. monilis R-PE. For the refinement of the two other structures the sequences of Porphyridium cruentum and Polysi phonia bol di i were used, respectively. Moreover, we were able to model three residues into the electron density that arises from the $\gamma$-polypeptide.

\section{MATERIALS AND METHODS}

Crystallization, data collection, and crystallographic computing. The purification, crystallization, and preliminary crystallographic characterization of R-PE from the red alga G. monilis have been described elsewhere (Ritter et al., 1997). For the solution of the structure at a resolution of $2.3 \AA$ we collected data from only one crystal (data set $A$ ) with a Stoe Imaging Plate detector system (Stoe, Darmstadt, Germany) at $14^{\circ} \mathrm{C}$. The X-ray source $(\mathrm{CuK} \alpha$ ) was a rotating anode (Stoe) operating at $40 \mathrm{kV}, 100$ $\mathrm{mA}$. For data reduction and determination of the space group (R3 with $a=b=187.35 \AA, c=59.31 \AA$ ) the XDS program (Kabsch, 1993) was used. High-resolution data were collected at the EMBL beamline $X 11$ at the Deutsches Elektronensynchrotron (DESY) in Hamburg, Germany, at $17^{\circ} \mathrm{C}$, using a MarResearch I mage Plate detector. Two crystals were used to obtain a complete data set extending to $1.82-\AA \AA$ resolution (data set B). Table I shows the statistics for both data sets. No indications for twinning, which is sometimes observed for crystals of phycobiliproteins, were found. All crystallographic computations, including molecular replacement, were carried out with X-PLOR 3.1 and 3.851 (Brünger, 1992, 1997).
Sequence determination, model building, and refinement. The sequence was obtained by genetic methods and was deposited with the EMBL database (Accession No. Z98528). An alignment with the sequences of R-PE from Pol. boldii (Roell and Morse, 1993), B-PE from Por. cruentum (Sidler et al., 1989), and C-PC from Fremyella diplosiphon (Mazel et al., 1988) is shown in Table II (for review see Apt et al., 1995). The coordinates of the 1CPC model (Duerring et al., 1991) were taken from the Brookhaven database and used for molecular replacement. Insertions and deletions relative to 1 CPC were modeled with "O" (J ones et al., 1991). For refinement, molecular dynamics and conventional energy restrained least-squares refinement procedures on positional parameters and B factors were used and water molecules were integrated into the model. A bulk solvent correction was included in the refinement procedure. The free R factor (Brünger, 1997) was used to optimize the refinement strategy.

\section{RESULTS}

\section{StructureSolution by Mol ecular Replacement}

As the unit cell parameters of R-PE resemblethose of ICPC, a similar packing was expected. This assumption was confirmed by a cross-rotation search. The $(\alpha \beta)_{2}$ dimer of 1CPC was placed into a triclinic unit cell $\left(a=155 \AA, b=90 \AA, c=100 \AA, \alpha=90^{\circ}\right.$, $\beta=90^{\circ}, \gamma=90^{\circ}$ ) and its Patterson was generated with reflections from 15 to $4 \AA$. The 1000 highest Patterson vectors were selected within the radius 45- $5 \AA$. The cross-rotation function was calculated in $2.5^{\circ}$ steps $\left(0 \leq \Theta_{+}<720^{\circ}, \quad 0 \leq \Theta_{2} \leq 180^{\circ}\right.$, $0 \leq \Theta_{-} \leq 120^{\circ}$; see Rao et al., 1980) in Lattman (1972) angle space and gave two clear maxima of equal height at Eulerian angles $-40^{\circ}, 0^{\circ}, 0^{\circ}$ and $90^{\circ}$, $180^{\circ}, 0^{\circ}$. These maxima are related by a $180^{\circ}$ rotation and correspond to the internal twofold symme try of the model dimer. The position of this twofold axis was confirmed by a self-rotation function with reflections within the range 15-4 $\AA$. The highest noise peak of the rotation function was at $95 \%$ of the height of the correct solutions but displayed a relative height of only $30 \%$ after Patterson correlation calculation.

As we anticipated from the packing constraints, the position corresponding to the highest peak (18\%) of the translation function showed that the "hexamer" axis coincides with the crystallographic threefold axis. Placing the model into the unit cell of the crystal yielded an initial R factor of $48.2 \%$ (6-3 $\AA$ ).

\section{TABLE I}

Data Statistics for the Observed Data Collected with the Stoe I mage Plate $(A)$ and at the EMBL Beamline X11 in Hamburg (B)

\begin{tabular}{|c|c|c|c|c|c|c|}
\hline $\begin{array}{l}\text { Data } \\
\text { set }\end{array}$ & $\begin{array}{l}\text { Resolu- } \\
\text { tion }(\AA)\end{array}$ & $\begin{array}{l}\text { Reflec- } \\
\text { tions }\end{array}$ & $\begin{array}{l}\text { Unique } \\
\text { reflections }\end{array}$ & $\begin{array}{c}I_{\text {unique }} \geq 3 \sigma \\
(\%)\end{array}$ & $\begin{array}{c}\text { Complete- } \\
\text { ness (\%) }\end{array}$ & $\begin{array}{c}\mathrm{R}_{\text {int }}{ }^{\mathrm{a}} \\
(\%)\end{array}$ \\
\hline \multirow[t]{2}{*}{$A$} & $10.00-2.30$ & 62202 & 33603 & 75.8 & 96.0 & 6.9 \\
\hline & $2.40-2.30$ & 5388 & 3093 & 47.0 & 44.8 & 21.9 \\
\hline \multirow[t]{2}{*}{ B } & $15.00-1.82$ & 131195 & 67598 & 59.5 & 96.8 & 5.9 \\
\hline & $2.00-1.82$ & 28679 & 15857 & 21.1 & 92.0 & 31.3 \\
\hline
\end{tabular}




\section{TABLE II}

Sequence Alignment between $\alpha$ - and $\beta$-Polypeptides of R-PE from Griffithsia monilis, R-PE from Polysi phonia bol dii, B-PE from Porphyridium cruentum, and C-PC from Fremyel la diplosiphon

(a) $\alpha$-Polypeptide

Sequence number: R-PE G. monilis R-PE Pol. boldii B-PE Por. cruentum C-PC F. diplosiphon Secondary structure

Sequence number: R-PE G. monilis R-PE Pol. boldii B-PE Por. cruentum C-PC F. diplosiphon Secondary structure

Sequence number: R-PE G. monilis R-PE Pol. boldii B-PE Por. cruentum C-PC F. diplosiphon Secondary structure

Sequence number: R-PE G. monilis R-PE Poly. boldii B-PE Por. cruentum C-PC F. diplosiphon Secondary structure

Sequence number: R-PE G. monilis R-PE Pol. boldii B-PE Por. cruentum C-PC F. diplosiphon Secondary structure

Sequence number: R-PE G. monilis R-PE Pol. boldii B-PE Por. cruentum C-PC F. diplosiphon Secondary structure

$10 \quad 20 \quad 30$

MKSVITTTISAADAAGRFPSSSDLESIOGNIORAAARIFAAOKLSGNHEAVVKEAGDACFAKYSYL- KNAGEAGDSPEKI

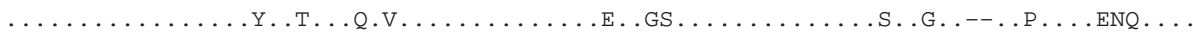

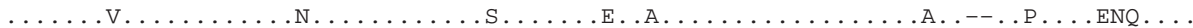

..TPL.EAVA...SQ...L. .TEIQTAF.RFRQ.S.S.A. KA.TEKASSLASG.AN.VYS.FP.TTSQ.GPNFASTQTGKD

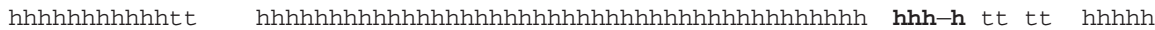

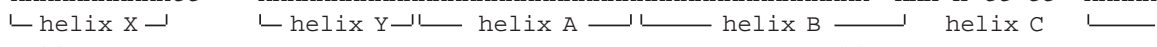
PEB $\alpha 82$

$\begin{array}{llllllll}* & 90 & 100 & 110 & 120 & 130 & * & 150\end{array}$

KCYRD IDHYMRLINYSLVVGGTGPVDEWGIAGSREVYRALNLPGSAYIAAFTFTRDRLCVPRDMSSQAGVEFTSALDYVI

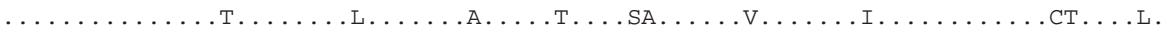

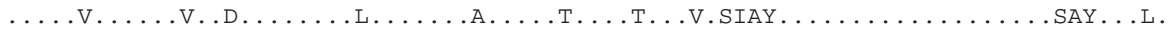
..V...GY.L.MVT.C.......L.DYL.G.IA.IN.TFD.SP.W.VE.LKYIKANHGL----.GDPA. .AN.YI. .A.

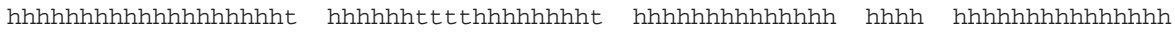

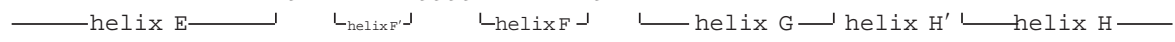

164

NSLC $\quad 164$

...S $\quad 164$

.A.S 164

.A.S 162

htt

\lrcorner$\quad$ (b) $\beta$-Polypeptide

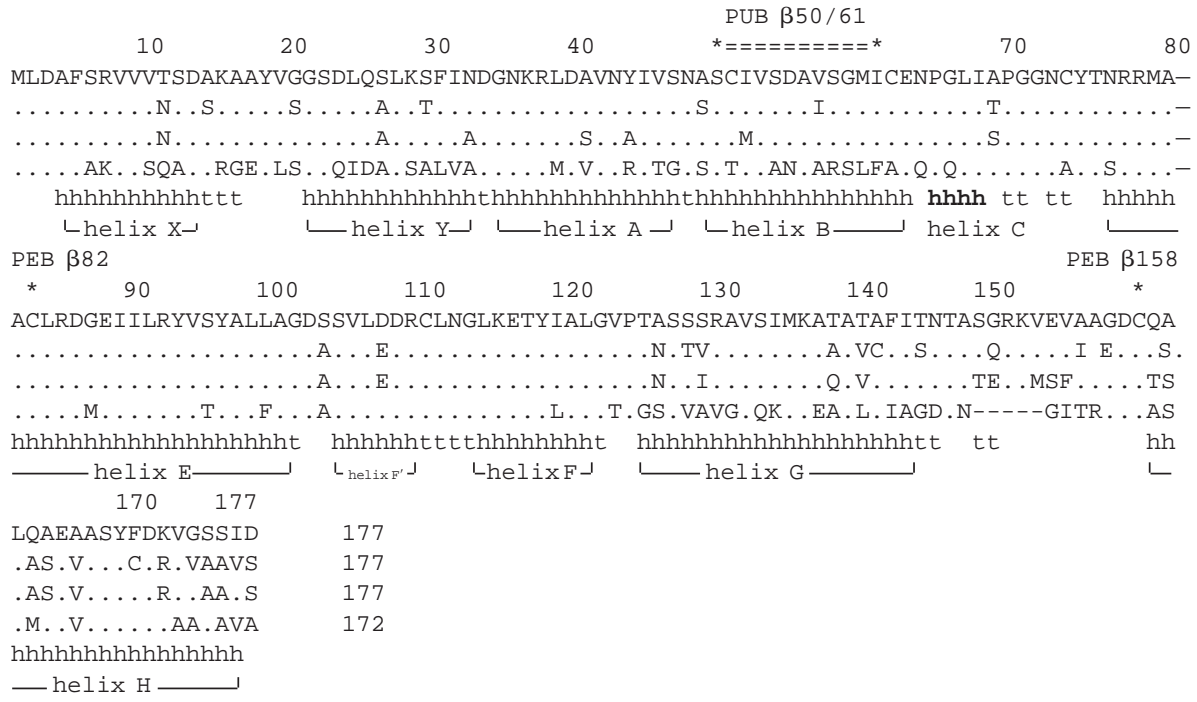

Note. Dots represent identical amino acids, and del etions are marked by dashes; secondary structure elements were determined using DSSP (Kabsch and Sander, 1983). h, 310-helix; h, $\alpha$-helix; t, turn. The nomenclature of the helices is according to Schirmer et al. (1985, 1987). An asterisk marks the position of the chromophores, $*===*$ indicates a doubly bound chromophore. Sequence numbers refer to $\mathrm{G}$. monilis.

\section{Model Building and Refinement}

The asymmetric unit of R-PE from $G$. monilis contains an $(\alpha \beta)_{2}$ dimer (ABKL) and on average $1 / 3$ of the $\gamma$-polypeptide, yielding a stoichiometry of $(\alpha \beta)_{2 \gamma 1 / 3}$. Before the first cycle of refinement, all side chains of the ICPC model were truncated to yield a polyAla(Gly) sequence and the chromophores were omitted. After completion of the X-PLOR refinement protocol (Brünger, 1997), a ( $\left.F_{\text {obs }}-F_{\text {calc }}\right)$ map and a $\left(2 \mathrm{~F}_{\text {obs }}-\mathrm{F}_{\text {calc }}\right)$ map were inspected and used for inserting a tentative amino acid sequence into the model.
As the amino acid sequence of $G$. monilis R-PE was initially not available, we used the sequence of Pol. boldii R-PE (Roell and Morse, 1993) for structure determination.

For refinement at high resolution the sequence of G. monilis R-PE was used and the resolution was increased to $1.90 \AA$ in a stepwise fashion. After inclusion of the majority of the water molecules, a bulk solvent correction was introduced, which re sulted in an improvement of the value of $R_{\text {free }}$ of approximately $1 \%$. At this stage three residues of the 
TABLE III

Parameters of the Refined R-PE Model

Number of nonhydrogen atoms

Number of chromophore atoms

Number of solvent molecules

$\mathrm{R}_{\text {work }}(\%)$

$\mathrm{R}_{\text {free }}(\%)$

Standard deviations from ideal values

Bond length $(\AA)$

Bond angles $\left({ }^{\circ}\right)$

Temperature factors $\left(\AA^{2}\right)$

Protein

Main chain atoms

Side-chain atoms

Chromophores

Solvent molecules
5855

430

333

17.5

22.7

0.004

1.1

22.1

20.8

23.7

24.2

33.6

$\gamma$-polypeptide were modeled into the electron density. Refinement of these residues indicated that they were fully occupied.

All residues of the $\alpha$ - and $\beta$-polypeptides as well as the chromophores could be built into the electron density. There are only a few solvent-exposed residues (insertion at position $\beta 147$ ) with disordered side chains. The density for the expected $\gamma-\mathrm{N}$ methylation of the asparagine residue at position $\beta 72$ was also very well defined. In contrast to the nomenclature used by Ficner and other authors (Schirmer et al., 1985, 1986, 1987; Duerring et al., 1990, 1991; Ficner et al., 1992; Chang et al ., 1996) we used a continuous numbering of the amino acid sequence. The final model $\left(R_{\text {work }}=17.5 \%\right.$, $\mathrm{R}_{\text {free }}=22.7 \%$ ) included 333 water molecules; its quality is summarized in Table III.

The mean positional error of the atoms as esti-

a

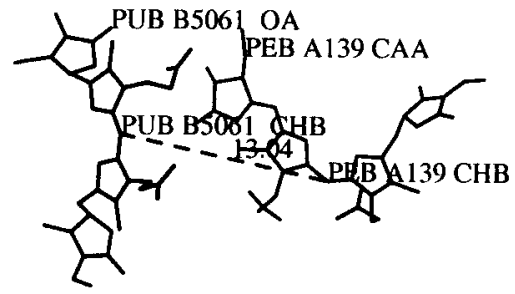

mated from a Luzzati (1952) plot is $0.27 \AA$. A Ramachandran (Ramachandran and Sasisekharan, 1968) plot shows that with the exception of the NCS-related residues Thr B75/L 75 (near $\phi=88^{\circ}$, $\psi=148^{\circ}$ ) all other residues fall into allowed regions. The peptide nitrogen atoms of $\mathrm{Thr}$ B 75/L 75 are hydrogen bonded to oxygen atoms OD of symmetryrelated PEBs at position $\alpha 82$. The el ectron densities of residues Thr B75/L 75 are well defined and their conformation is highly conserved among all phycobiliprotein structures (Schirmer et al., 1985, 1986, 1987; Duerring et al., 1990, 1991; Brejc et al., 1995; Chang et al., 1996).

The atomic coordinates of the refined model have deviations of bond lengths and bond angles from ideality of $0.004 \AA$ and $1.1^{\circ}$, respectively. They are available from the Brookhaven Protein Data Bank (Entry No. 1B8D).

\section{DISCUSSION}

\section{Crystal Packing and Protein Contacts}

The structure of R-PE from the red alga G. monilis was solved by the method of molecular replacement, using $1 C P C$ as a model, and refined at $1.90-\AA$ resolution. Though the parameters of the unit cells are very similar and the positions of the helices within the proteins are almost identical, there is a striking difference in the packing of $1 \mathrm{CPC}$ and R-PE : the columns of hexamers are rotated by $-40^{\circ}$ around the $z$ axis, so that different intercolumn contacts are formed. Obviously, due to the approximate cylindrical symmetry of the columns, different packing arrangements can be accommodated within a similar unit cell. A special feature of the crystal packing in

b
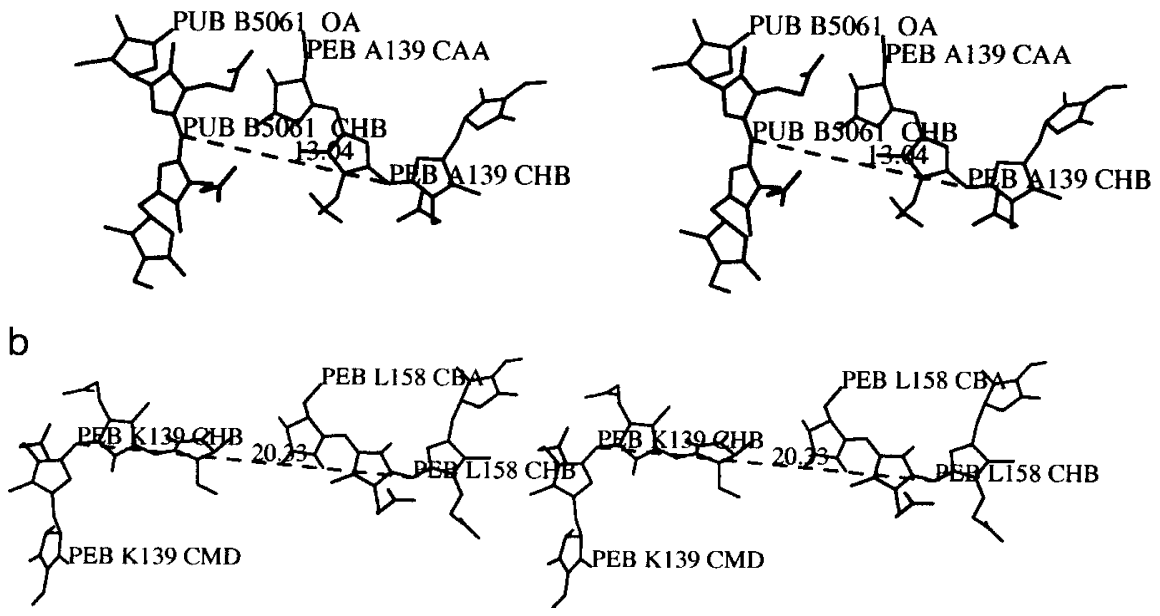

FIG. 2. (a) Relative orientation (stereo view) of the chromophores PUB B50/61 and PEB A139 of a symmetry-related $\alpha$-pol ypeptide. The distance between the centers of gravity of these two chromophores is approximately $13.0 \AA$. (b) Relative orientation (stereo view) of the chromophores PEB K 139 and PE B L 158 of a symmetry-related $\beta$-polypeptide. The cl osest distance between these two chromophores is 3.4 $\AA$, while the distance between their centers of gravity is $20.3 \AA$. 

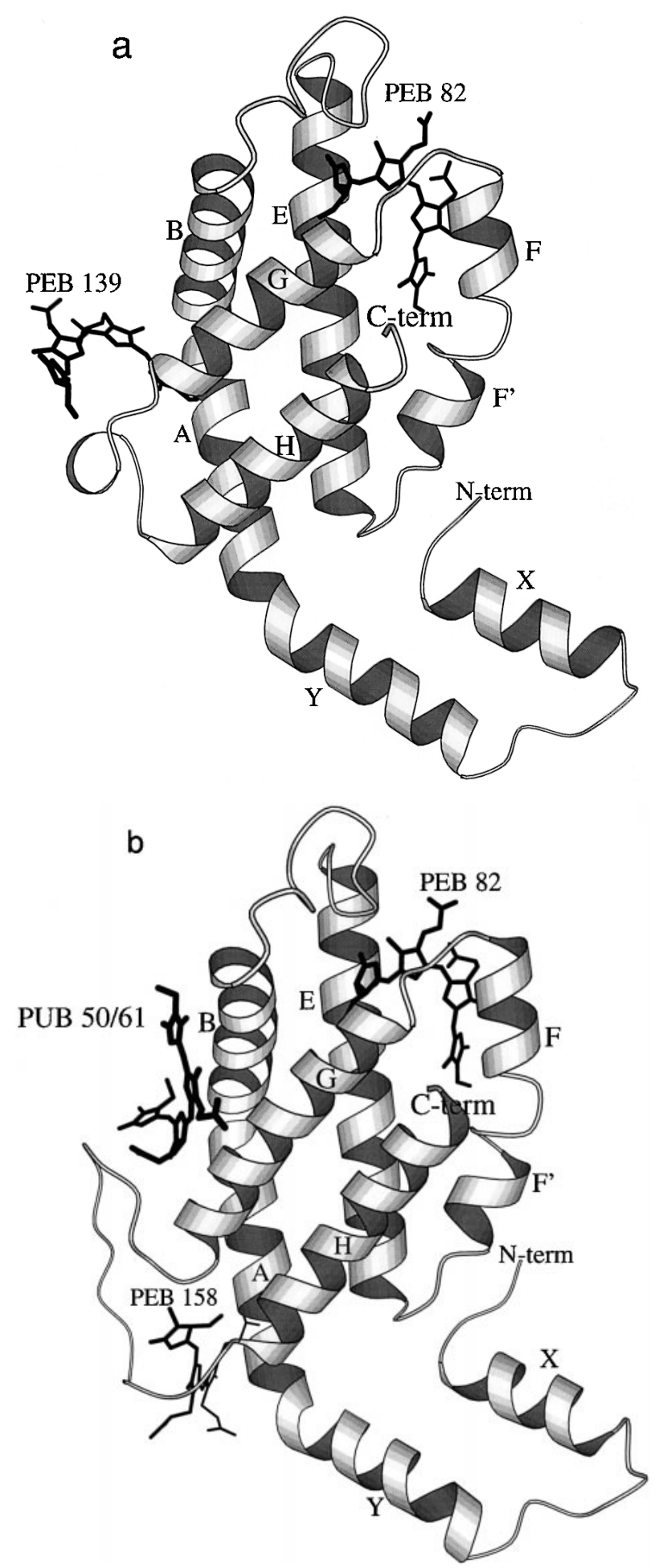

FIG. 3. Ribbon representation of (a) the $\alpha$-polypeptide and (b) the $\beta$-polypeptide. The chromophores are shown as thick lines. Plots were produced with Molscript (Kraulis, 1991). this R-PE structure is the chromophore-protein crystal contact between PEB K139 and the residues Cys L158 and GIn L159 on a symmetry-related $\beta$-polypeptide. The protein-protein contacts are predominantly made by the loops between helices $\mathrm{G}$ and $\mathrm{H}$ of the $\alpha$ - and the $\beta$-polypeptides.

In R-PE the crystal packing makes it possible for PUB at position B50/61 on subunit B to come close to PEB at position A139 of a symmetry related $\alpha$-polypeptide. The distance between the centers of gravity of these two chromophores is approximately $13.0 \AA$, and their orientation relative to each other is almost perpendicular (Fig. 2a). There is also a short distance between chromophore PEB K 139 and chromophore PEB L 158 of a symmetry-related $\beta$-polypeptide. The closest distance between these two chromophores is $3.4 \AA$, while the distance between their centers of gravity is $20.3 \AA$, resulting from a parallel arrangement of these chromophores ( $F$ ig. 2b). F urthermore there is a close distance between PEB K139 and PUB L50/61 of a symmetry-related $\beta$-polypeptide. The distance between their centers of gravity is approximately $16.5 \AA$ and their relative orientation is almost perpendicular. Thus, the crystal packing in R-PE could make an exciton interaction possible as an artifact of the crystalline state. Compared to the ILIA entry in the Brookhaven database the arrangement of the chromophores within the crystal packing is the same for R-phycoerythrin from Pol. urceolata.

\section{Molecular Structure}

$\alpha$ - and $\beta$-Polypeptides. As in many other known phycobiliproteins the two polypeptides $\alpha$ and $\beta$ of R-PE from G. monilis are arranged as an $(\alpha \beta)_{6}$ hexamer with the $\gamma$-polypeptide located in the central cavity. The $\alpha$-polypeptide contains 164 residues and the $\beta$-polypeptide contains 177 residues. The percentage of helix contents in the $\alpha$ - and the $\beta$-polypeptides is 79 and $73 \%$, respectively.

The main structural difference from 1CPC is a deletion of two amino acids at position $\alpha 76$ (C-terminus of helix $\mathrm{C}$ ) and an insertion of four amino acids at position $\alpha 138$ ( $\mathrm{N}$-terminus of helix $\mathrm{H}^{\prime}$, corresponding to position $\alpha 140$ in B-PE, including the attachment site of PEB $\alpha 139$ ) of the $\alpha$-polypeptide, as well as an insertion of five amino acids at position $\beta 145$ (corresponding to position $\beta 147$ in B-PE) of the $\beta$-polypeptide.

A comparison of the structure of R-PE from G. monilis with the ILIA and the ICPC entry shows root-mean-square (rms) deviations for $\mathrm{C}_{\alpha}$ atoms (using a distance cutoff of $3.8 \AA$ ) of $0.50 \AA$ for $682 \mathrm{C} \alpha$ atoms for $1 \mathrm{LI} A$ and $1.06 \AA$ for 655 atoms for 1 CPC.

Figure 3 shows the polypeptide chain of $\mathrm{G}$. monilis $\mathrm{R}-\mathrm{PE}$ as a ribbon trace together with the chromo- 
TABLE IV

Protein Environment of the Chromophores

\begin{tabular}{|c|c|c|c|c|c|}
\hline Chromophore atom & PEB A82 & PEB A139 & PEB B82 & PEB B158 & PUB B50/61 \\
\hline OA & 3.5 GlyA73-N & & 3.5 CysB 73-SG & 3.3 GlyB156-N & 3.5 SerB 147-OG \\
\hline & 3.4AlaA 72-O & & 3.3 AsnB 72-OD1 & 3.5 AlaB 154-O & 2.9 GlyB $148-N$ \\
\hline NA & 3.5 AlaA 72-O & & 2.9AsnB72-OD1 & 2.9 AlaB 154-O & \\
\hline & 3.4 CysA82-SG & & & 3.7 CysB 158-SG & \\
\hline NB & 2.7 AspA85-OD2 & $\begin{array}{l}2.7 \mathrm{~W} 383-\mathrm{OH} 2 \\
\text { 3.1 ArgA } 142-\mathrm{NH} 1\end{array}$ & 2.7 AspB85-OD2 & 2.6 AspB39-OD2 & 2.8AspB54-OD2 \\
\hline O1B & & 3.0 ArgA 137-NH2 & $\begin{array}{l}\text { 2.7 W548-OH2 } \\
\text { 3.5 ArgB 77-NH1 } \\
\text { 3.0 ArgB 77-NH2 }\end{array}$ & $\begin{array}{l}2.9 \mathrm{~W} 402-\mathrm{OH} 2 \\
3.5 \mathrm{~W} 482-\mathrm{OH} 2\end{array}$ & 3.6 SerB 147-N \\
\hline $\mathrm{O} 2 \mathrm{~B}$ & $\begin{array}{l}2.8 \mathrm{~W} 549 \mathrm{OH} 2 \\
3.0 \text { SymW456-OH2 }\end{array}$ & $\begin{array}{l}\text { 3.3 ArgA137-NH1 } \\
\text { 3.2 ArgA137-NH2 }\end{array}$ & $\begin{array}{l}\text { 3.1 ArgB 77-NH2 } \\
\text { 2.7 ArgB 78-NE }\end{array}$ & $2.6 \mathrm{~W} 482-\mathrm{OH} 2$ & 2.7 SerB147-OG \\
\hline NC & $\begin{array}{l}\text { 2.9 AspA85-OD2 } \\
\text { 3.4AspA85-OD1 } \\
\text { 3.4ArgA84-NH2 }\end{array}$ & $\begin{array}{l}\text { 3.0 W383-OH2 } \\
\text { 3.2 ArgA } 137-\mathrm{NH} 1\end{array}$ & $\begin{array}{l}\text { 2.9 AspB 85-OD2 } \\
\text { 3.2 AspB 85-OD1 } \\
\text { 3.4 ArgB84-NH2 }\end{array}$ & $\begin{array}{l}\text { 2.7 AspB39-OD2 } \\
\text { 3.6 W420-OH2 }\end{array}$ & $\begin{array}{l}2.7 \text { AspB54-OD2 } \\
3.3 \mathrm{~W} 443-\mathrm{OH} 2\end{array}$ \\
\hline $\mathrm{O} 1 \mathrm{C}$ & $\begin{array}{l}2.7 \mathrm{~W} 345 \mathrm{OH} 2 \\
2.8 \text { ArgA84-NH1 } \\
\text { 2.7 ArgA84-NH2 }\end{array}$ & $\begin{array}{l}\text { 2.8 ArgA142-NH2 } \\
\text { 2.6 W470-OH2 }\end{array}$ & $\begin{array}{l}\text { 2.8ArgB 84-NH } 1 \\
\text { 2.9ArgB 84-N } 2\end{array}$ & & $2.8 \mathrm{~W} 467-\mathrm{OH} 2$ \\
\hline $\mathrm{O} 2 \mathrm{C}$ & $\begin{array}{l}2.8 \text { LysA81-NZ } \\
\text { 2.8 SymW456-OH2 }\end{array}$ & 3.2 ArgA142-NH2 & $\begin{array}{l}2.8 \text { W465-OH } 2 \\
2.7 \text { W548-OH } 2\end{array}$ & & $\begin{array}{l}\text { 3.4 ArgB } 129-\mathrm{NH} 1 \\
3.5 \text { W358-OH2 }\end{array}$ \\
\hline $\begin{array}{l}\text { ND } \\
\text { OD }\end{array}$ & $\begin{array}{l}\text { 3.0 W345 OH } 2 \\
2.9 \text { W314 OH } 2 \\
\text { 3.0 SymThrB 75-N }\end{array}$ & $\begin{array}{l}2.9 \text { W470-OH2 } \\
2.9 \text { AsnA47-ND2 } \\
3.1 \text { W494-OH2 }\end{array}$ & & $\begin{array}{l}\text { 3.0 AsnB35-OD1 } \\
\text { 2.9 GInA28-NE } 2\end{array}$ & $\begin{array}{l}2.7 \mathrm{W626-OH2} \\
2.8 \mathrm{~W} 555-\mathrm{OH} 2 \\
3.3 \mathrm{CysB} 61-\mathrm{SG}\end{array}$ \\
\hline
\end{tabular}

Note The distance is given in $\AA$ directly before the respective hydrogen-bond partner.

phores. A detailed description of the protein environment of the chromophores is given in Table IV.

Chromophores. R-PE has three PEBs $(\alpha 82, \beta 82$, and $\beta 158)$ at equivalent chromophore positions as in ICPC. Two additional chromophores, one PEB and one PUB, were found in the structure at equivalent

\section{TABLE V}

Stereochemistry and Conformation of the Chromophores of Subunits A and B of R-PE

\begin{tabular}{lccccc}
\hline \multicolumn{1}{c}{ Chromophore } & PEB & PEB & PEB & PEB & PUB \\
Chiral atoms & A139 & B82 & B158 & B50/61 \\
C-2 & & & & & \\
C-3 & $\mathrm{R}$ & $\mathrm{R}^{\mathrm{a}}$ & $\mathrm{R}$ & $\mathrm{R}$ & - \\
C-3' & $\mathrm{R}$ & $\mathrm{R}$ & $\mathrm{R}$ & $\mathrm{R}$ & - \\
C-4 & $\mathrm{R}$ & $\mathrm{R}^{\mathrm{a}}$ & $\mathrm{R}$ & $\mathrm{S}$ & $\mathrm{S}$ \\
C-16 & $\mathrm{R}$ & - & - & - & $\mathrm{S}$ \\
C-18' & - & - & - & - & $\mathrm{R}$ \\
Conformation of & & & & & \\
$\quad$ double bonds & & & & & \\
C ${ }_{4}^{\text {(ring A-B) }}$ & Z-anti & Z-anti & Z-anti & Z-anti & - \\
C ${ }_{10}$ (ring B-C) & Z-syn & Z-syn & Z-syn & Z-syn & Z-syn \\
\hline
\end{tabular}

Note. The conformations of the chromophores on the related subunits $K$ and $L$ are the same. The nomenclature of the chromophore atoms is given in Fig. 1 . The positions $3^{\prime}$ and $18^{\prime}$ indicate the binding of the chromophore to the protein. syn, synperiplanar; anti, antiperiplanar; - , not a chiral atom.

a For the determination of the stereochemistry PEB K 139 was used, as the electron density of the methyl group of the chromophore PE B A139 was weak due to strong exposure of the chromophore to the solvent. positions as in B-PE from Por. sordidum and R-PE from Pol. urceolata. The PEB chromophore is covalently bound to a Cys residue by ring $A$. It is located at position $\alpha 139$ on a solvent-exposed loop of the $\alpha$-polypeptide, protruding from the protein and connecting helices $G$ and $H^{\prime}$. The doubly linked PUB is bound to Cys $\beta 50$ on helix $B$ of the $\beta$-polypeptide with ring $A$ and to Cys $\beta 61$ on the same helix with
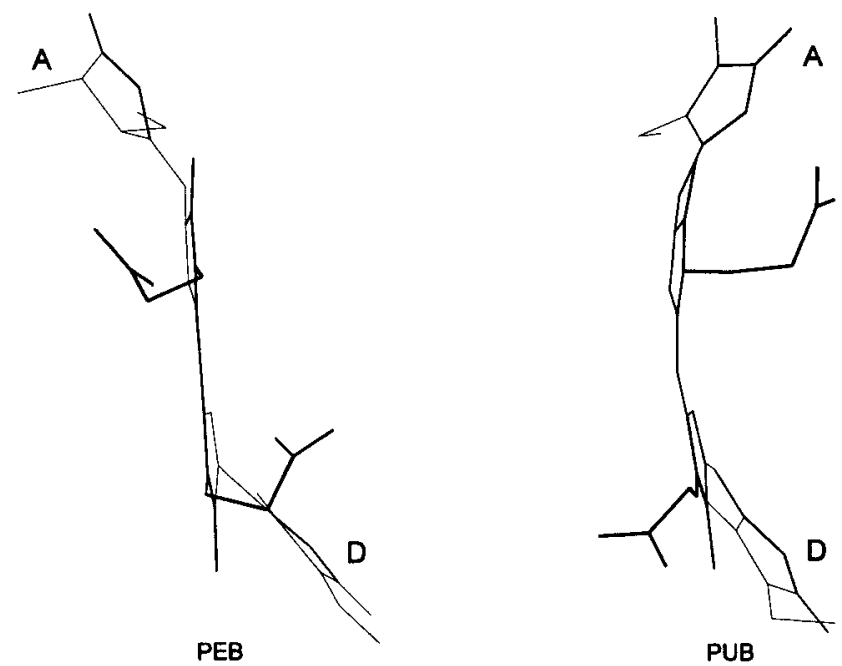

FIG. 4. Conformation of PEB $\beta 82$ and PUB $\beta 50 / 61$ chromophores. The conformation of all other $\mathrm{PEB}$ chromophores is very similar. Rings $B$ and $C$ of the chromophores point toward the reader, while rings $A$ and $D$ point in the opposite direction. The boat-like conformation of PUB can clearly be seen. 


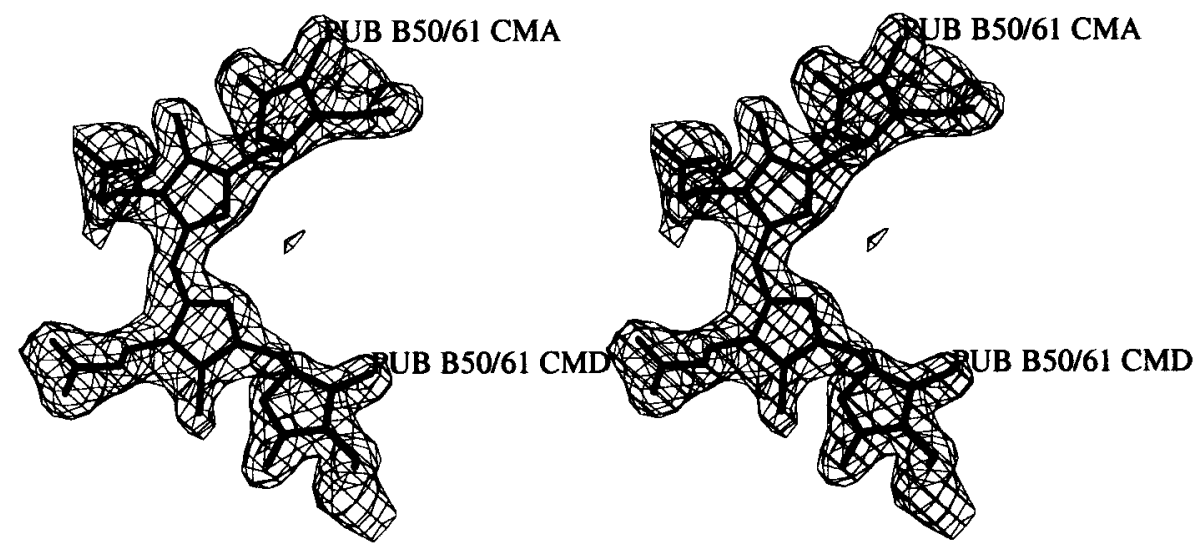

FIG. 5. Stereo view of chromophore PUB $\beta 50 / 61$. The $2 F_{\text {obs }}-F_{\text {calc }}$ density map is displayed at $1.0 \sigma$. Ring $A$ of the chromophore is on the top of the drawing.

ring $D$. The stereochemistry of the chromophores PEB $\alpha 82, \alpha 139, \beta 82$, and $\beta 158$ is identical to the stereochemistry of the chromophores of B-PE from Por. sordidum (for the nomenclature of the chromophore atoms see Fig. 1). The stereochemistry of the atoms C-2 and C- $3^{\prime}$ of the chromophore PEB A139 was derived from the symmetry-related chromophore PEB K139, as the electron density of the methyl group CMA of PEB A139 was weak due to the strong exposure to the solvent. The ster eochemistry of the individual chromophores is given in Table V.

The conformation of the PUB chromophore differs strongly from the conformation of the PEB chromophores. In PUB, rings $A$ and $D$ are located on the same side of the chromophore plane built by rings $B$ and $\mathrm{C}$, whereas in all PEB chromophores these two

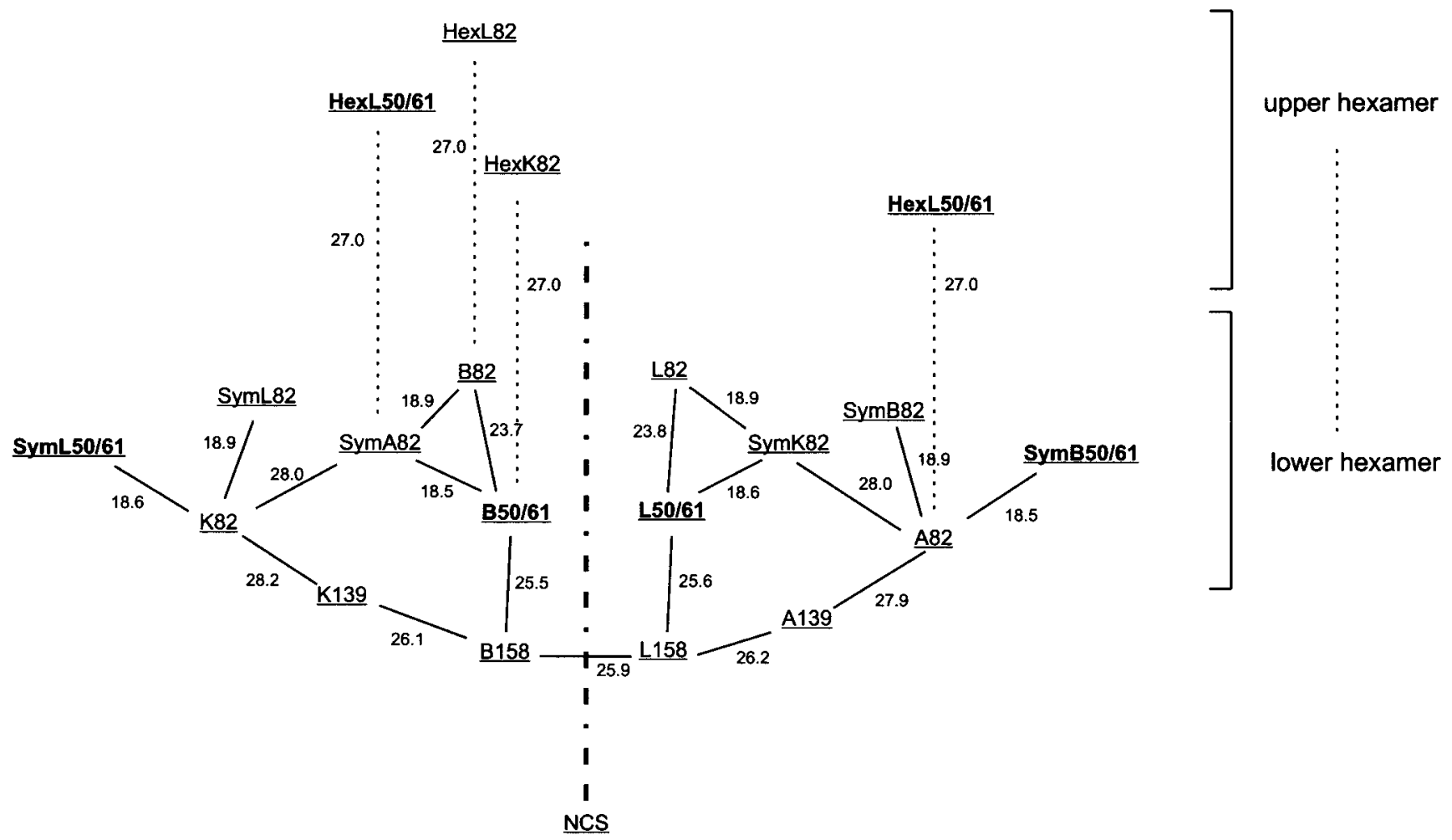

FIG. 6. Schematic presentation of the arrangement and distances of the chromophores in the asymmetric unit $A B K L$. The chromophores are projected into the xy plane, and the view is in z along the crystallographic threefold axis. The NCS symmetry of the asymmetric unit is shown. Distances are given in $\AA$. Only distances $<30 \AA$ are shown for sel ected chromophores. Sym, symmetry-related chromophores within the R-PE hexamer; Hex, symmetry-related chromophores of two stacked hexamers. 


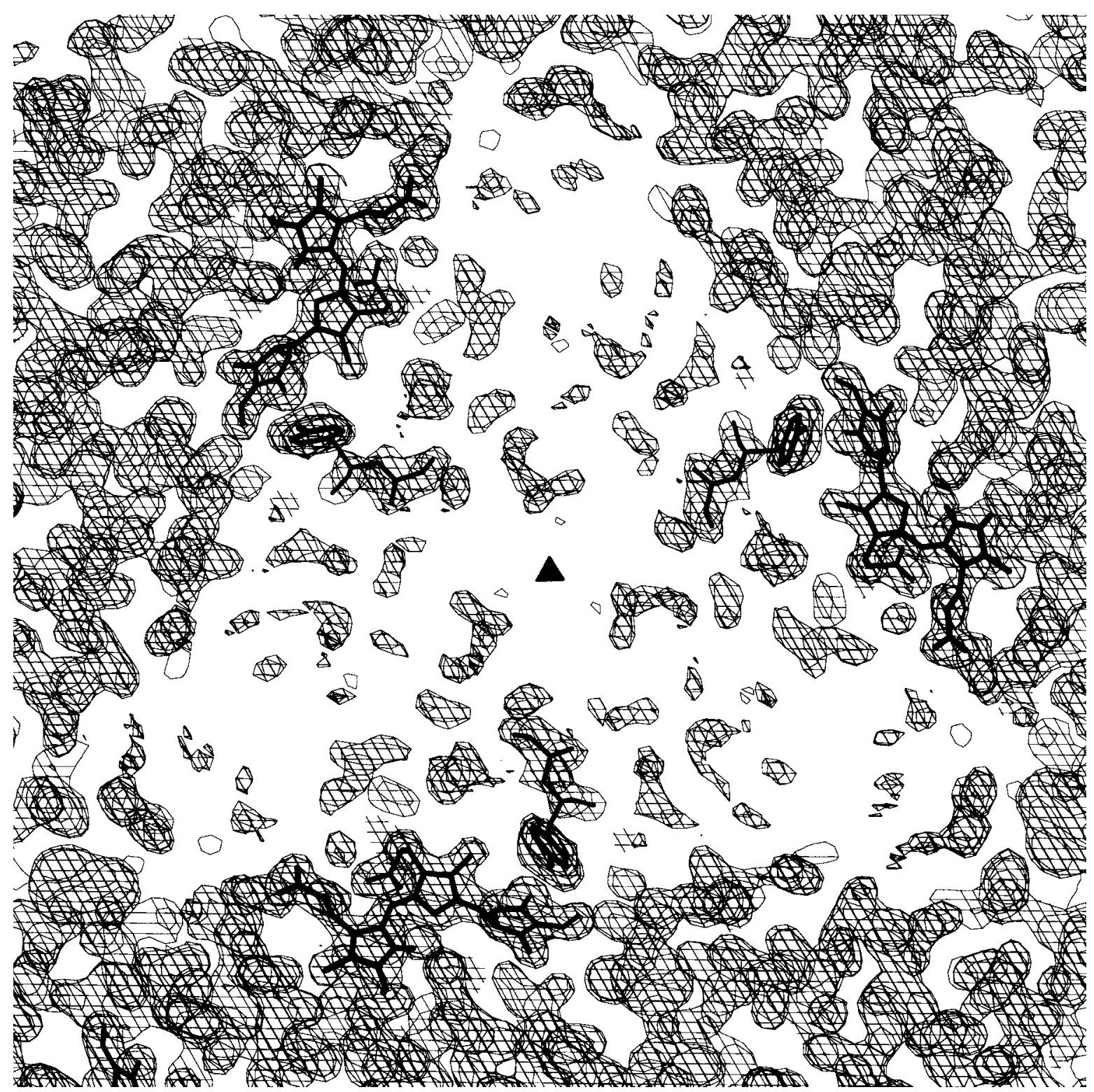

FIG. 7. Slab of the electron density in the central cavity of R-PE displayed at $1 \sigma$. This segment of electron density encompasses the symmetry related chromophores PE B B82 together with dipeptides Gly G1-Tyr G2 (heavy lines) of the $\gamma$-polypeptide. The crystallographic threefold axis is indicated.

rings are found on different sides of the chromophore plane. Figure 4 shows the "boat-like" conformation of PUB together with the " $z$ " conformation of the PEB chromophores. The stereochemistry of the PUB could be determined accurately (Table V) due to the high resolution of the structure and the very-well-defined electron density of the chromophore. Looking at the ILI A entry, PUB in Pol. urceolata seems to be more evenly bent than the PUB in G. monilis, which makes an exact determination of the stereochemistry difficult and is probably an artifact of the lower resolution of that study $(2.8 \AA)$. Figure 5 shows the chromophore PUB B50/61 in R-PE from G. monilis within a $\left(2 \mathrm{~F}_{\text {obs }}-\mathrm{F}_{\text {calc }}\right)$ density map displayed at $1.0 \sigma$.

Energy transfer. Though the absorption maximum of PUB ( $\lambda_{\max }$ at $498 \mathrm{~nm}$ ) is at a much shorter wavelength than the absorption maximum of the PEB ( $\lambda_{\max }$ at 535-567 nm) chromophores (Apt et al., 1995), PUB is not isolated in the periphery of the protein, building the starting point of an energy transfer pathway in a single disc but is rather located in the vicinity of the chromophores PEB $\beta 82$ and PEB $\beta 158$ and a symmetry-related chromophore PEB $\alpha 82$ within the hexamer. It is also close to a symmetry-related PEB $\alpha 82$ in the hexamer stack 

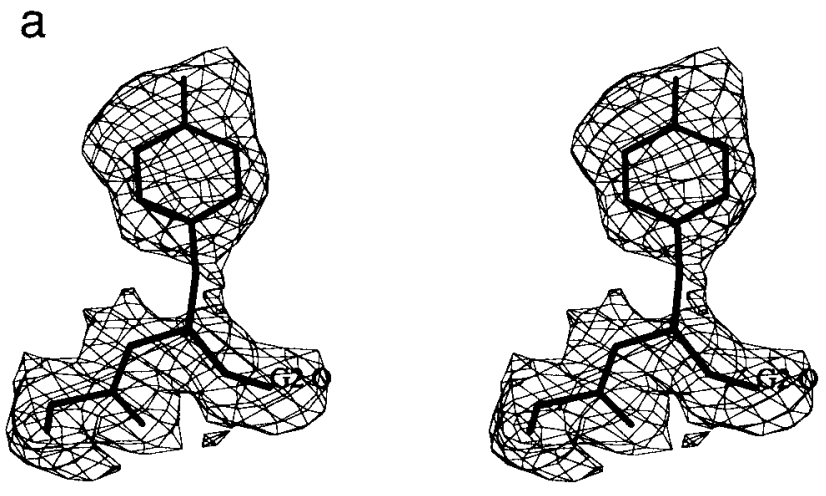

b
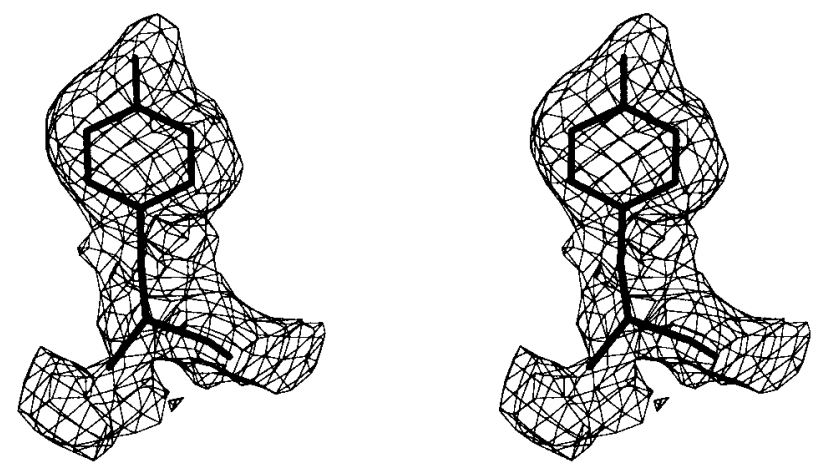

FIG. 8. (a) Stereo view of the dipeptide Gly G1-Tyr G2. The $2 \mathrm{~F}_{\text {obs }}-\mathrm{F}_{\text {calc }}$ density map is displayed at $0.8 \sigma$. (b) Stereo view of Tyr G3. The $2 \mathrm{~F}_{\text {obs }}-\mathrm{F}_{\text {calc }}$ density map is displayed at $0.8 \sigma$.

(Fig. 6). Assuming a suitable orientation of the transition dipole moments of the chromophores, it is possible that PUB not only absorbs light in the blue region of the spectrum, but also takes part in the energy transfer within a single disc as described for PEB $\beta 50 / 61$ in the structure of B-PE from Por. sordidum (Ficner et al., 1992). Figure 6 shows schematically the relative orientation of the chromophores in the asymmetric unit of R-PE and lists the shortest distances between them. In addition, some symmetry-related chromophores within the same hexamer and between a stack of hexamers are shown.

Looking at the distances $(<30 \AA)$ between neighboring chromophores in the R-PE hexamer, we observed two prominent distances: 18.5 and $26 \pm 2 \AA$. Ficner et al. (1992) observed similar distances for the chromophores in B-PE (19.5 and $25 \pm 3.5 \AA$ ). Calculating the energy transfer rates in B-PE, they found that the transfer of energy is not primarily related to the distance between the chromophores as similar distances between chromophores did not account for similar energy transfer rates. This indicates that the orientation of the chromophores in phycobiliproteins is not only optimized for energy transfer to the photosynthetic reaction center but is al so a prerequi- site for an effective capture of light energy and its interim storage in the antenna complex.

$\gamma$-Polypeptide SDS-PAGE indicates that there are at least two different $\gamma$-polypeptides present in the crystals of R-PE (Ritter et al., 1997); however, only isolated spots of weak electron density showing a threefold symmetry could be observed in the center of the $(\alpha \beta)_{6}$ hexamer (Fig. 7), so that the $\gamma$-polypeptide cannot be clearly seen in a $\left(2 \mathrm{~F}_{\text {obs }}-\mathrm{F}_{\text {calc }}\right)$ electron density map.

A careful inspection of a $\left(\mathrm{F}_{\text {obs }}-\mathrm{F}_{\text {calc }}\right)$ difference map displayed at $4 \sigma$, however, revealed a strong differencein el ectron density inside the $(\alpha \beta)_{6}$ hexamer in close proximity to the chromophores PEB B82 and PEB L82 that could not be explained by the initial model. We interpreted this el ectron density as deriving from amino acid residues of the $\gamma$-polypeptide and modeled one dipeptide (Gly G1-Tyr G2) and one single amino acid (Tyr G3) into well-defined regions of this density near chromophore PEB B82 and chromophore PEB L82, respectively. Both Tyr residues are related by the same NCS dyad as the chromophores. Figure 8 shows the residues with their $\left(2 \mathrm{~F}_{\text {obs }}-\mathrm{F}_{\text {calc }}\right)$ electron density, displayed at $0.8 \sigma$.

In contrast to the residue Tyr G3, the electron density for Tyr G2 was not ideally defined as it was, in principle, possible to model either a Tyr or a Trp residue. In particular the density of the $C \beta$ atom of Tyr G2 is defined only at a low sigma cut $(0.8 \sigma)$. However, as a Tyr residue fitted the density best and taking into account the fact that $\mathrm{G} 2$ and $\mathrm{G} 3$ are related by the NCS dyad, we modeled the difference el ectron density as Tyr G2. The side chains of Tyr G2 and Tyr G3 are both in close proximity (3.5-3.7 $\AA$ ) to ring $D$ of the chromophores PEB B82 and PEB L82, respectively (Fig. 9). Tyr G3 is hydrogen-bonded to the peptide oxygen of residue Cys $L 109$ (3.3 $\AA$ ), while the corresponding distance between Tyr G2 and Cys $\mathrm{B} 109$ is about $3.7 \AA$. This shows that the hydrophobic pockets of chromophores PEB B82 and PEB L82 are partly built by the $\gamma$-polypeptide rather than being completed by the $(\alpha \beta)_{6}$ hexamer. As a consequence, both chromophores are shiel ded against the chromophores of the $\gamma$-polypeptide by the polypeptide backbone of these residues, which inhibits close contact between the chromophores of the $\beta$-polypeptide and the $\gamma$-polypeptide. This would make an exciton exchange rather improbable and would instead favor a Förster (1965) mechanism for energy transfer.

The fact that the $\gamma$-polypeptide cannot be seen in the electron density was also reported for B-PE (Ficner et al., 1992) and R-PE (Chang et al., 1996) and is due to the incompatibility of the $(\alpha \beta)_{6} \gamma$ stoichiometry with the threefold symmetry of the lattice, as the $\gamma$-polypeptides show no threefold 
a
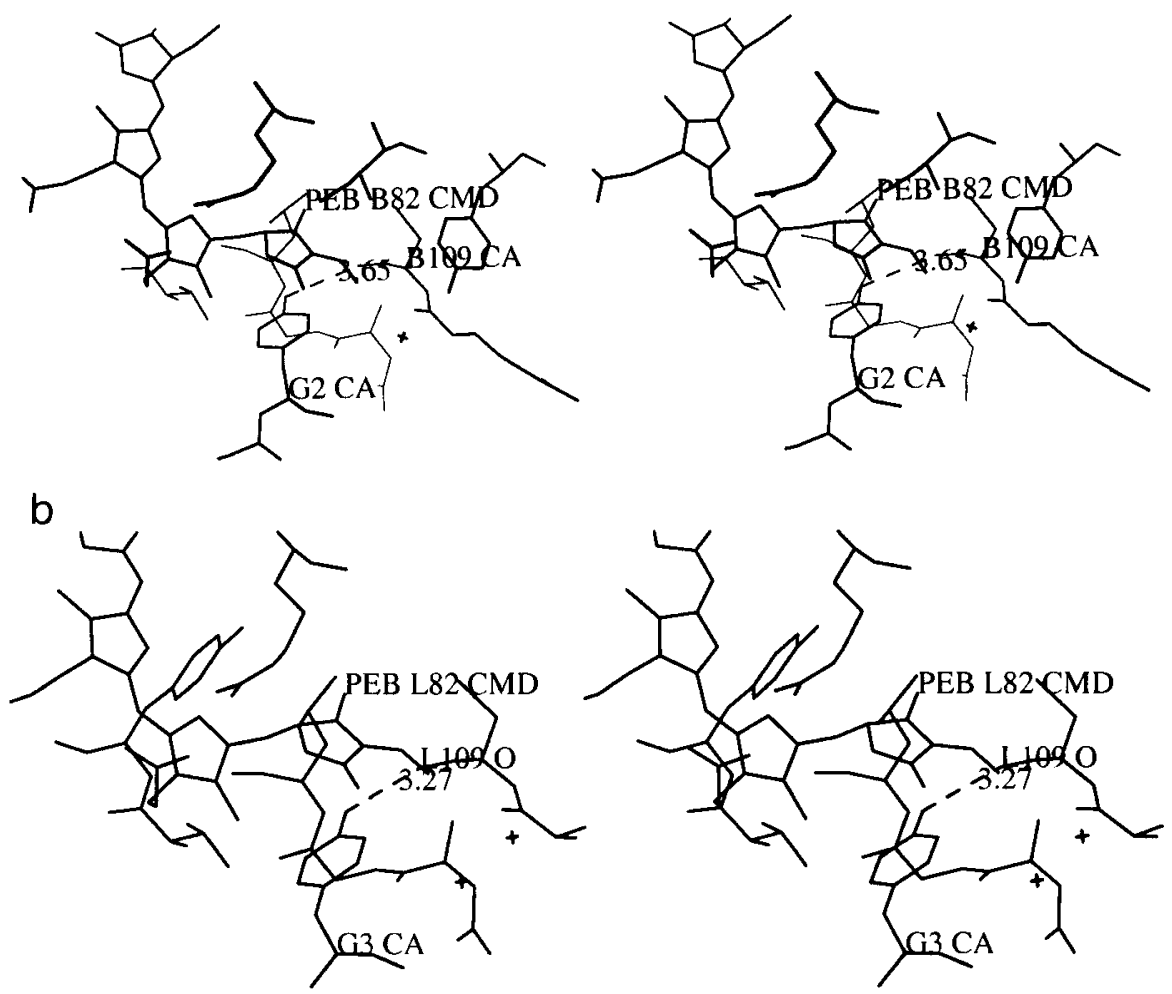

FIG. 9. (a) Protein environment of the residues Gly G1-Tyr G2 of the $\gamma$-polypeptide. (b) Protein environment of Tyr G3 of the $\gamma$-polypeptide.

symmetry in their sequence (Apt et al., 1993; Ficner and Huber, 1993). Thus, the $\gamma$-polypeptides are present in the crystal, but their arrangement within the hexamers is statistical, so that their electron density is averaged. Looking at the sequence of the $\gamma$-polypeptide of R-PE from Aglaothamnion neglectum (Apt et al., 1993) we found 18 Tyr residues, 6 of which we would expect to be involved in the interaction with the PE B chromophores at position $\beta 82$ due to the occupancy refinement results.

\section{Conclusions}

With the exception of the bilins occurring in cryptophytes, the structures of most other phycobilins (PCB, PXB, PEB, and PUB) have been solved. The future goal is to determine the structure of the linker proteins and complexes of phycobiliproteins together with linker proteins. In this respect, the structure of R-PE reported here could allow the modeling of a separately determined $\gamma$-polypeptide into the hexamer using the two symmetry-related Tyr positions reported here as markers.

We thank Frank Sharples for his expert assistance in culturing Griffithsia.
Noteadded in proof. Therefinement of R-PE from Polysiphonia urceolata at $1.9 \AA$ resolution has recently been reported (J iang et al., 1999).

\section{REFERENCES}

Apt, K. E., Hoffman, N. E., and Grossman, A. R. (1993) The $\gamma$-subunit of R-phycoerythrin and its possible mode of transport into the plastid of red algae, J . Biol . Chem. 268, 16208-16215.

Apt, K. E., Collier, J . L., and Grossman, A. R. (1995) Evolution of the phycobiliproteins, J . Mol. Biol. 248, 79-96.

Betz, M. (1997) One century of protein crystallography: The phycobiliproteins, Biol. Chem. 378, 167-176.

Brejc, K., Ficner, R., Huber, R., and Steinbacher, S. (1995) I solation, crystallization, crystal structure analysis and refinement of allophycocyanin from the cyanobacterium Spirulina platensis at 2.3 Å resolution, J . Mol. Biol . 249, 424-440.

Brünger, A. T. (1992) "X-plor Version 3.1: A System for X-ray Crystallography and NMR."Yale University.

Brünger, A. T. (1997) Free R value: Cross-validation in crystallography, in Carter, C. W., and Sweet, R. M. (Eds.), Methods in Enzymology, Vol. 277, pp. 243-269, Academic Press, San Diego.

Chang, W., J iang, T., Wan, Z., Zhang, J ., Yang, Z., and Liang, D. (1996) Crystal structure of R-phycoerythrin from Polysiphonia urceolata at $2.8 \AA$ resolution, J. Mol. Biol . 262, 721-731.

Duerring, M., Huber, R., Bode, W., Ruembeli, R., and Zuber, H. (1990) Refined three dimensional structure of phycoerythrocyanin from the cyanobacterium Mastigocladus laminosus at $2.7 \AA$, J. Mol. Biol. 211, 633-644.

Duerring, M., Schmidt, G. B., and Huber, R. (1991) Isolation, 
crystallization, crystal structure analysis and refinement of constitutive C-phycocyanin from the chromatically adapting cyanobacterium Fremyella diplosiphon at $1.66 \AA$ resolution, J . Mol. Biol. 217, 577-592.

Ficner, R., and Huber, R. (1993) Refined crystal structure of phycoerythrin from Porphyridium cruentum at $0.23 \mathrm{~nm}$ resolution and localization of the $\gamma$-subunit, Eur. J . Biochem. 218, 103-106.

Ficner, R., Lobeck, K., Schmidt, G., and Huber, R. (1992) I solation crystallization, crystal structure analysis and refinement of B-phycoerythrin from the red alga Porphyridium sordidum at 2.2 A resolution, J. Mol. Biol. 228, 935-950.

Förster, T. (1965) Delocalized excitation and excitation transfer, in Sinanoglu, O. (Ed.), Modern Quantum Chemistry, Part III, pp. 93-137, Academic Press, New York.

Gantt, E., and Lipschultz, C. (1973) Energy transfer in phycobilisomes from phycoerythrin to phycocyanin, Biochem. Biophys. Acta 292, 858-861.

Glazer, A. N. (1985) Light harvesting by phycobilisomes, Annu. Rev. Biophys. Biophys. Chem. 14, 47-77.

Glazer, A. N. (1989) Light guides: Directional energy transfer in a photosynthetic antenna, J . Biol. Chem. 264, 1-4.

Glazer, A. N., Apell, G. S., Hixson, C. S., Bryant, D. A., Rimon, S., and Brown, D. M. (1976) Biliproteins of Cyanobacteria and Rhodophyta: Homologous family of photosynthetic accessory pigments, Proc. Natl. Acad. Sci. USA 73, 428-431.

Grossman, A. R., Schaefer, M. R., Chiang, G. G., and Collier, J . L. (1993) The phycobilisome, a light-harvesting complex responsive to environmental conditions, Microbiol. Rev. 57, 725-749.

Huber, R. (1989) A structural basis of light energy and electron transfer in biology, EMBO J . 8, 2125-2147.

J iang, T., Zhang, J.-P., and Liang, D.-C. (1999) Structure and Function of Chromophores in R-Pycoerythrim at $1.5 \AA$ resolution, Proteins: Struct., Funct. and Genet. 34, 224-231.

J ones, T. A., Zou, J .-Y., Cowan, S. W., and Kjeldgaard, M. (1991) Improved methods for building protein models in electron density maps and the location of errors in these models, Acta Crystallogr. Sect. A 47, 110-119.

Kabsch, W. (1993) Automatic processing of rotation diffraction data from crystals of initially unknown symmetry and cell constants, J . Appl . Crystallogr. 26, 795-800.

Kabsch, W., and Sander, C. (1983) Dictionary of protein secondary structure: Pattern recognition of hydrogen-bonded and geometrical features, Biopolymers 22, 2577-2637.

Kraulis, P. J . (1991) Molscript: A program to produce both detailed and schematic plots of protein structures, J. Appl. Crystallogr. 24, 946-950.
Lattman, E. E. (1972) Optimal sampling of the rotation function, Acta Crystallogr. Sect. B 28, 1065-1068.

Luzzati, P. V. (1952) Traitement statistique des erreurs dans la détermination des structures cristallines, Acta Crystallogr. 5, 802-810.

MacColl, R., and Guard-Friar, D. (1987) Phycobiliproteins, CRC Press, Boca Raton, FL.

Mazel, D., Houmard, J., and Tandeau de Marsac, N. (1988) A multigene family in Calothrix sp. PCC 7601 encodes phycocyanin, the major component of the cyanobacterial light-harvesting antenna, Mol. Gen. Genet. 211, 296-304.

Ramachandran, G. N., and Sasisekharan, V. (1968) Conformation of polypeptide and proteins, Adv. Protein Chem. 23, 283-437.

Rao, S. N., J ih, J .-H., and Hartsuck, J . A. (1980) Rotation-function space groups, Acta Crystallogr. Sect. A 36, 878-884.

Ritter, S., Hiller, R. G., Wrench, P. M., Wacker, T., Welte, W., and Diederichs, K. (1997) Purification, crystallization and preliminary X-ray analysis of a phycourobilin-containing phycoerythrin, Protein Peptide Lett. 4, 69-74.

Roell, M. K., and Morse, D. E. (1993) Organization, expression and nucleotide sequence of the operon encoding R-phycoerythrin $\alpha$ and $\beta$ subunits from the red alga Polysiphonia boldii, Plant Mol. Biol. 21, 47-58.

Sauer, K. (1975) in Govindjee (Ed.), Bioenergetics of Photosynthesis, p. 115, Academic Press, San Francisco.

Schirmer, T., Bode, W., Huber, R., Sidler, W., and Zuber, H. (1985) $X$-ray crystallographic structure of the light-harvesting biliprotein C-phycocyanin from thethermophilic cyanobacterium Mastigocladus laminosus and its resemblance to globin structures, J . Mol. Biol. 184, 257-277.

Schirmer, T., Huber, R., Schneider, M., Bode, W., Miller, M., and Hackert, M. L. (1986) Crystal structure analysis and refinement at $2.5 \AA$ of hexameric C-phycocyanin from the cyanobacterium Agmenel lum quadruplicatum, J . Mol. Biol. 188, 651-676.

Schirmer, T., Bode, W., and Huber, R. (1987) Refined threedimensional structures of two cyanobacterial C-phycocyanins at 2.1 and $2.5 \AA$ resolution, J . Mol. Biol. 196, 677-695.

Sidler, W., Kumpf, B., Suter, F., Klotz, A. V., Glazer, A. N., and Zuber, H. (1989) The complete amino-acid sequence of the $\alpha$ and $\beta$ subunits of B-phycoerythrin from the Rhodophytan alga Porphyridium cruentum, Biol. Chem. HoppeSeyler 370, 115124.

Stadnichuk, I. N., Khokhlachev, A. V., and Tikhonova, Y. V. (1993) Polypeptide $\gamma$-subunits of R-phycoerythrin, J . Photochem. Photobiol. B Biol. 18, 169-175. 